\title{
ARTICLE
}

Received 29 May 2014 | Accepted 10 Oct 2014 | Published 20 Nov $2014 \quad$ DOl: 10.1038/ncomms6537

\section{Mercury nano-trap for effective and efficient removal of mercury(II) from aqueous solution}

\author{
Baiyan $\mathrm{Li}^{1}$, Yiming Zhang ${ }^{1}$, Dingxuan $\mathrm{Ma}^{2}$, Zhan $\mathrm{Shi}^{2} \&$ Shengqian $\mathrm{Ma}^{1}$
}

Highly effective and highly efficient decontamination of mercury from aqueous media remains a serious task for public health and ecosystem protection. Here we report that this task can be addressed by creating a mercury 'nano-trap' as illustrated by functionalizing a high surface area and robust porous organic polymer with a high density of strong mercury chelating groups. The resultant porous organic polymer-based mercury 'nano-trap' exhibits a recordhigh saturation mercury uptake capacity of over $1,000 \mathrm{mg} \mathrm{g}^{-1}$, and can effectively reduce the mercury (II) concentration from 10 p.p.m. to the extremely low level of smaller than 0.4 p.p.b. well below the acceptable limits in drinking water standards (2 p.p.b.), and can also efficiently remove $>99.9 \%$ mercury(II) within a few minutes. Our work therefore presents a new benchmark for mercury adsorbent materials and provides a new perspective for removing mercury(II) and also other heavy metal ions from contaminated water for environmental remediation.

\footnotetext{
${ }^{1}$ Department of Chemistry, University of South Florida, 4202 E. Fowler Avenue, Tampa, Florida 33620, USA. ${ }^{2}$ State Key Laboratory of Inorganic Synthesis and Preparative Chemistry, College of Chemistry, Jilin University, Changchun 130012, China. Correspondence and requests for materials should be addressed to S.M. (email: sqma@usf.edu).
} 
M ercury $(\mathrm{Hg})$ pollution, which can cause birth defects, brain damage, and disease in humans and other species, has long been a threat to public health and environment $^{1}$. The release of mercury into environments is mainly through discharge from industry products/byproducts and processes, such as chemicals, electronic materials, batteries and fossil fuel combustion ${ }^{2}$. A global agreement has recently been reached aiming at reducing mercury's threat, which spurs the research needed to remove and recover mercury ions from industry waste water ${ }^{3}$. An upper limit of 2 p.p.b. for mercury in drinking water has been mandated by the United States Environmental Protection Agency (EPA) ${ }^{4}$, and even much lower limits have been strictly regulated for the discharge of mercury into aquatic systems to protect ecosystems ${ }^{5}$.

Among various technologies developed over the years for mercury removal, adsorption holds great promise due to the simplicity and relatively low-cost of adsorption technology as well as the effectiveness of adsorption method to purify water ${ }^{6}$. A variety of adsorbents have been developed and tested for removing $\mathrm{Hg}(\mathrm{II})$ from contaminated waters. Conventional adsorbents such as activated carbons ${ }^{7}$, zeolites ${ }^{8}$ and clays ${ }^{9}$ generally have low capacity and weak binding affinity for mercury. Thiol/thio-functionalized adsorbents, including clays ${ }^{10}$, resins $^{11}$, mesoporous silica ${ }^{12-16}$, activated carbons ${ }^{17}$, mesorporous carbons $^{18}$ and chalcogenides ${ }^{19,20}$, are considered very effective sorbents for $\mathrm{Hg}$ (II) removal from aqueous solutions due to the soft-soft interaction ${ }^{21}$. Recently, metal-organic frameworks $(\mathrm{MOFs})^{22-28}$ have been explored as a new type of adsorbents for mercury removal ${ }^{29-34}$ due to their high surface areas, but they usually suffer from instability in water ${ }^{29,30}$ or aqueous solutions with a wide $\mathrm{pH}$ range $\mathrm{e}^{34}$ and possess low adsorption capacity and weak affinity for $\mathrm{Hg}$ (II).

Until now, existing adsorbent materials still face sorts of challenges such as the low surface area and improper distribution of thio/thiol groups thereby low capacity and moderate affinity for $\mathrm{Hg}(\mathrm{II})$, leaching of sulfur element and poor stability in a wide $\mathrm{pH}$ range, which have largely limited their effectiveness and efficiency for the removal of $\mathrm{Hg}$ (II) from aqueous solutions. The weaknesses and handicaps associated with existing adsorbents necessitate the development of new types of materials for highly effective and highly efficient removal of $\mathrm{Hg}$ (II) from aqueous solutions.

To tackle the aforementioned challenges, in this contribution we illustrate a new approach by creating mercury 'nano-trap' (Fig. 1) that features high surface area with densely populated yet highly accessible $\mathrm{Hg}(\mathrm{II})$ binding sites thereby affording high $\mathrm{Hg}$ (II) adsorption capacity; strong $\mathrm{Hg}$ (II) chelating groups that are well dispersed throughout the single-walled pore surface thus rendering high affinity for $\mathrm{Hg}(\mathrm{II})$ and efficient utilization of $\mathrm{Hg}$ (II) binding sites; large yet tunable pore size to enable fast yet controllable kinetics of $\mathrm{Hg}(\mathrm{II})$ adsorption; $\mathrm{Hg}$ (II) chelating groups that are covalently anchored to the backbone thus avoiding the leaching of binding sites; exceptional water/chemical stability facilitating regeneration/recyclability. Such mercury 'nano-trap' can be targeted by grafting desired $\mathrm{Hg}$ (II) chelating

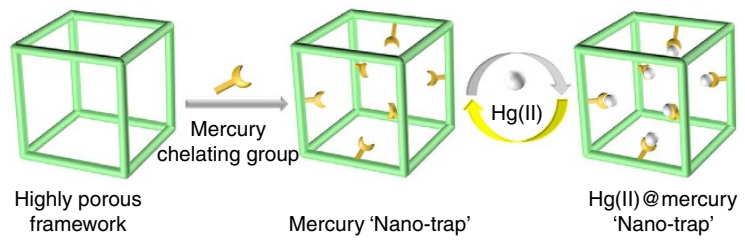

Figure 1 | 'Nano-trap' for $\mathbf{H g}$ (II) removal. Illustration of creating mercury 'nano-trap' for $\mathrm{Hg}(\mathrm{II})$ removal from water. groups to the highly robust porous organic polymers (POPs) $)^{35-44}$ that exhibit high surface areas, tunable pore sizes and high water/ chemical stabilities, via stepwise post-synthetic modification ${ }^{45}$ of the phenyl rings of their structural components using various established organic reactions. Herein we demonstrate such a POP-based mercury 'nano-trap' that exhibits an exceptional mercury saturation uptake capacity of over $1,000 \mathrm{mg} \mathrm{g}^{-1}$ and can effectively reduce $\mathrm{Hg}$ (II) concentration from 10 p.p.m. to the extremely low level of smaller than 0.4 p.p.b. and can efficiently remove $>99.9 \%$ mercury within a few minutes, outperforming the performances of existing mercury removal adsorbents. Moreover, the POP-based mercury 'nano-trap' is highly effective for mercury removal over a very broad $\mathrm{pH}$ range and can be readily regenerated and recycled without significant loss of mercury adsorption capacity.

\section{Results}

Synthesis and characterization. The POP-based mercury 'nanotrap' was afforded by functionalizing PAF-1 (ref. 46) (also known as PPN-6 (ref. 38)), an amorphous POP (Supplementary Fig. 1) that exhibits very high surface area and exceptional water/ chemical stability, with thiol groups that are well-known to bind $\mathrm{Hg}$ (II) strongly. The thiol-functionalized PAF-1 (PAF-1-SH) was prepared by chloromethylation of PAF-1 followed by the treatment with NaHS (Supplementary Figs 2 and 3).

The successful grafting of thiol group onto PAF-1 was confirmed by Fourier transform infrared spectroscopy (FT-IR), X-ray photoelectron spectroscopy (XPS) and solid-state ${ }^{13} \mathrm{C}$ NMR studies. The FT-IR spectra of the dehydrated PAF-1-SH show the aliphatic C-H stretching bands at $2,959 \mathrm{~cm}^{-1}$ and $2,928 \mathrm{~cm}^{-1}$ as well as the characteristic band ${ }^{47}$ of S-H at $2,576 \mathrm{~cm}^{-1}$ compared with the pristine PAF-1 (Supplementary Fig. 4). XPS spectra of PAF-1-SH indicate the appearance of sulfur signal at a binding energy of $163.8 \mathrm{eV}$ (Supplementary Fig. 5), which is consistent with the $S(2 p)$ of the thiol group ${ }^{48}$. Solid-state ${ }^{13} \mathrm{C}$ NMR studies identify the chemical shifts at 23.0 and 28.9 p.p.m. for the carbon of $-\mathrm{CH}_{2}$ group (Supplementary Fig. 6), suggesting the successful attachment of $-\mathrm{CH}_{2} \mathrm{SH}$ groups to the phenyl rings in PAF-1. Elemental analysis reveals a sulfur content of $17.6 \mathrm{wt} . \%$ corresponding to $5.5 \mathrm{mmol} \mathrm{g}^{-1}-\mathrm{SH}$ groups in PAF-1-SH, which indicates $57 \%$ of the phenyl rings are grafted with one $-\mathrm{CH}_{2} \mathrm{SH}$ group each.

Nitrogen gas sorption isotherms collected at $77 \mathrm{~K}$ indicate that the grafting of thiol groups leads to a decrease in the BrunauerEmmett-Teller (BET) surface area from $4,715 \mathrm{~m}^{2} \mathrm{~g}^{-1}$ for PAF-1 to $3,274 \mathrm{~m}^{2} \mathrm{~g}^{-1}$ for PAF-1-SH and a small reduction in pore size by about $3 \AA$ (Fig. 2b). It is worth noting that the surface area of PAF-1-SH is significantly higher than any other thiol-modified porous materials, which usually exhibit moderate surface areas of $500 \sim 2,000 \mathrm{~m}^{2} \mathrm{~g}^{-1}$ (refs 7-20,29,31-33). In addition, the sulfur content in PAF-1-SH is also remarkably higher compared with
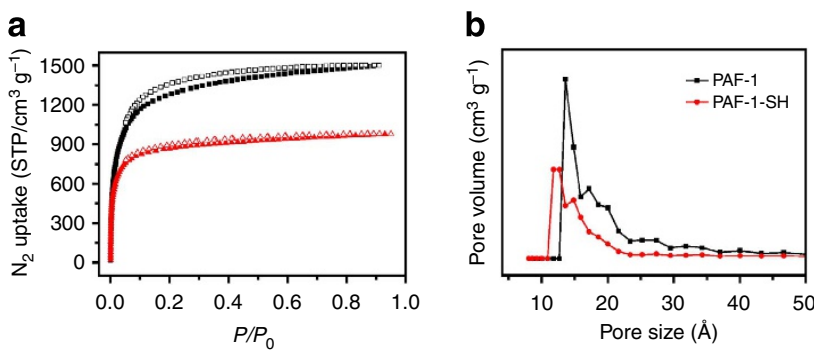

Figure $\mathbf{2} \mid \mathbf{\mathbf { N } _ { \mathbf { 2 } }}$ sorption isotherms and pore size distributions.

(a) $\mathrm{N}_{2}$ sorption isotherms of PAF-1 (black) and PAF-1-SH (red)

(b) Pore size distributions of PAF-1 (black) and PAF-1-SH (red). 
thiol group functionalized mesoporous silica MCM-41 (MCM41-SH) (17.6 wt.\% in PAF-1-SH versus 4.99 wt.\% in MCM-41$\mathrm{SH})$. The high surface area and densely populated thiol groups prompt us to evaluate PAF-1-SH as mercury 'nano-trap' for $\mathrm{Hg}$ (II) removal from aqueous solutions.

Hg(II) sorption studies. To evaluate the effectiveness of PAF-1SH as mercury 'nano-trap' for removing $\mathrm{Hg}$ (II) from water, an asmade PAF-1-SH sample was placed in a dilute aqueous solution ( $\mathrm{pH}$ of 6.8 ) of $\mathrm{Hg}\left(\mathrm{NO}_{3}\right)_{2}$ with $\mathrm{Hg}$ (II) concentration of 10 p.p.m. The adsorbed $\mathrm{Hg}(\mathrm{II})$ was observed by Energy-dispersive X-ray spectroscopy (EDS) spectra and sulfur from the thio group was also detected by EDS (Supplementary Fig. 7). As shown in Fig. 3a, PAF-1-SH can rapidly capture $\mathrm{Hg}$ (II) ions; and after $\sim 6 \mathrm{~h}$ the residual $\mathrm{Hg}(\mathrm{II})$ concentration in the solution was smaller than 0.4 p.p.b., that is, almost $99.997 \%$ of the mercury was removed by PAF-1-SH under such condition. It is noteworthy that the residual $\mathrm{Hg}(\mathrm{II})$ concentration in the solution treated with PAF-1-SH is 28 times lower than that (0.01 p.p.m.) in the solution treated with the MOF of $\mathrm{Zr}-\mathrm{DMBD}^{34}$, and is also lower than that in the solution treated with thiol group functionalized FMMS (0.8 p.p.b.) (ref. 12) or Chalcogel-1 (0.04 p.p.m.) (ref. 19). These results therefore highlight the superior effectiveness of PAF-1-SH for removing $\mathrm{Hg}$ (II) from aqueous solutions compared with some benchmark sorbents. Indeed a single treatment of highly contaminated water with PAF-1-SH can effectively reduce the mercury concentration to well below U.S. Environmental Protection Agency elemental limits for hazardous wastes and even the acceptable limits in drinking water standards $(<2 \text { p.p.b. })^{4}$. We reasoned that the high effectiveness of PAF-1$\mathrm{SH}$ for mercury removal from aqueous solutions should be attributable to its high affinity for $\mathrm{Hg}$ (II) as a result of the highly accessible thiol groups that are densely populated throughout the inner surface of PAF-1-SH.

One measure of a sorbent's affinity for a target metal ion is the distribution coefficient $\left(K_{d}\right)$ measurement ${ }^{49}$. The $K_{d}$ is defined as:

$$
K_{d}=\frac{\left(C_{i}-C_{f}\right)}{C_{f}} \times \frac{V}{m}
$$

where $C_{i}$ is the initial metal ion concentration, $C_{f}$ is the final equilibrium metal ion concentration, $V$ is the volume of the treated solution ( $\mathrm{ml}$ ) and $m$ is the mass of sorbent used $(\mathrm{g})$. The $K_{d}$ represents an important aspect of any sorbent's performance metrics of metal ion adsorption, and $K_{d}$ values of $1.0 \times 10^{5} \mathrm{mlg}^{-1}$ are usually considered excellent ${ }^{18}$. The $K_{d}$ of PAF-1-SH for $\mathrm{Hg}(\mathrm{II})$ has been measured to be exceptional with a value of $5.76 \times 10^{7} \mathrm{mlg}^{-1}$. This value is among the highest for sorbent materials for $\mathrm{Hg}$ (II) adsorption reported thus far, and exceeds that reported for a series of benchmark materials, for

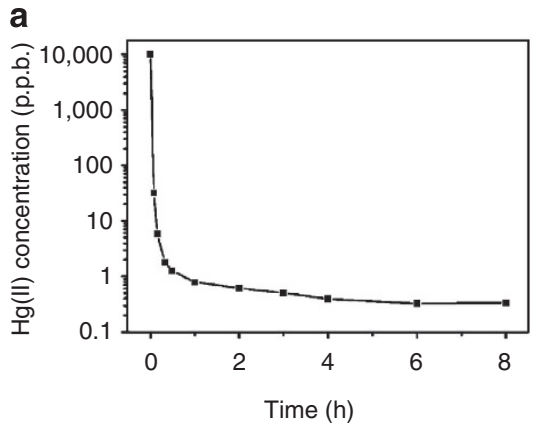

example, commercial resins $\left(10^{4} \sim 5.10 \times 10^{5} \mathrm{mlg}^{-1}\right)^{50}$, FMMS $\left(3.4 \times 10^{5} \sim 1.68 \times 10^{7} \mathrm{ml} \mathrm{g}^{-1}\right)^{12,13}$ thiopyrene-functionalized mesoporous carbon $\left(6.82 \times 10^{5} \mathrm{mlg}^{-1}\right)^{18}$, LHMS-1 $(6.4 \times$ $\left.10^{6} \mathrm{ml} \mathrm{g}^{-1}\right)^{50}$, Chalcogel-1 $\left(1.61 \times 10^{7} \mathrm{mlg}^{-1}\right)^{19}$ and the MOF of $\mathrm{Zr}-\mathrm{DMBD}\left(9.99 \times 10^{5} \mathrm{ml} \mathrm{g}^{-1}\right)^{34}$.

The efficiency of PAF-1-SH as mercury 'nano-trap' for removing $\mathrm{Hg}$ (II) from aqueous solutions has been examined by investigating the mercury adsorption kinetics of PAF-1-SH $(25.0 \mathrm{mg})$ in 10 p.p.m. solution ( $\mathrm{pH}$ of 6.8$)$ of $\mathrm{Hg}\left(\mathrm{NO}_{3}\right)_{2}$ $(50.0 \mathrm{ml})$. As shown in Fig. 3b, extremely fast kinetics are observed for PAF-1-SH, which can attain $99.9 \%$ of the adsorption capacity at equilibrium within $7 \mathrm{~min}$ and is able to reduce a heavily contaminated water with the $\mathrm{Hg}$ (II) concentration of 10 p.p.m. to the acceptable limit of 2 p.p.b. for drinking water within $<20 \mathrm{~min}$ of PAF-1-SH/water contact (Fig. 3a). Considering the great reliability to represent the kinetics for the adsorption of heavy metal ions from aqueous solutions onto adsorbents ${ }^{51}$, the experimental data were fitted with the pseudo-second-order kinetic model using the following equation:

$$
\frac{t}{q_{t}}=\frac{1}{k_{2} q_{e}^{2}}+\frac{t}{q_{e}}
$$

where $k_{2}\left(\mathrm{~g} \mathrm{mg}^{-1} \mathrm{~min}^{-1}\right)$ is the rate constant of pseudo-secondorder adsorption, $q_{t}\left(\mathrm{mgg}^{-1}\right)$ is the amount of $\mathrm{Hg}$ (II) adsorbed at time $t(\mathrm{~min})$, and $q_{e}\left(\mathrm{mgg}^{-1}\right)$ is the amount of $\mathrm{Hg}(\mathrm{II})$ adsorbed at equilibrium. An extremely high correlation coefficient $(>0.9999)$ was obtained (Fig. 3b), and the value of the adsorption rate constant $k_{2}$ was determined to be $8.13 \mathrm{~g} \mathrm{mg}^{-1} \mathrm{~min}^{-1}$. This value is one or two orders of magnitude higher than other adsorbent materials for $\mathrm{Hg}(\mathrm{II})$ adsorption under similar conditions ${ }^{32,52-54}$, and such extraordinarily fast kinetics observed for PAF-1-SH can be ascribed to its large pore size adequately to facilitate the diffusion of $\mathrm{Hg}(\mathrm{II})$ ions and its high surface area densely populated with thiol groups.

To assess the mercury uptake capacity of PAF-1-SH, which is also an important aspect of sorbent's performance metrics, adsorption isotherm for $\mathrm{Hg}(\mathrm{II})$ removal from water ( $\mathrm{pH}$ of 6.8) was collected (Fig. 4). The equilibrium adsorption isotherm data were fitted with Langmuir model ${ }^{34,52}$ yielding a high correlation coefficient ( $>0.9984)$ (Fig. 4 inset). Remarkably, the maximum mercury adsorption capacity of PAF-1-SH was calculated to be $1,014 \mathrm{mg} \mathrm{g}^{-1}\left(\sim 5.1 \mathrm{mmol} \mathrm{g}^{-1}\right)$. This corresponds to the capture of $0.927 \mathrm{Hg}(\mathrm{II})$ ion per thiol group in $\mathrm{PAF}-1-\mathrm{SH}$, suggesting the accessibility of almost all thiol groups in PAF-1-SH for $\mathrm{Hg}(\mathrm{II})$ ions. To the best of our knowledge, the maximum mercury uptake capacity of PAF-1-SH is the highest among adsorbent materials reported thus far for mercury adsorption, and is significantly higher than that of some

\section{b}

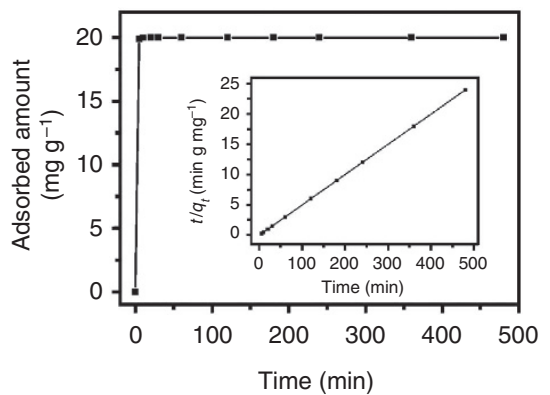

Figure 3 | Kinetics investigation of PAF-1-SH. (a) Hg(II) sorption kinetics of PAF-1-SH under the $\mathrm{Hg}(\mathrm{II})$ initial concentration of 10 p.p.m. (b) Adsorption curve of $\mathrm{Hg}(\mathrm{II})$ versus contact time in aqueous solution using PAF-1-SH. Inset shows the pseudo-second-order kinetic plot for the adsorption ( $\mathrm{Hg}(\mathrm{II})$ concentration: 10 p.p.m.). 
benchmark thiol/thio-functionalized porous materials, for example, thiol-monolayer-functionalized mesoporous silica $\left(505 \sim 600 \mathrm{mg} \mathrm{g}^{-1}\right)^{12,13}$, thiopyrene-featured porous carbon $\left(518 \mathrm{mgg}^{-1}\right)^{18}$ Chalcogel-1 $\left(645 \mathrm{mgg}^{-1}\right)^{19}$ MOF Zr-DMBD $\left(197 \mathrm{mg} \mathrm{g}^{-1}\right)^{34}$. Such an outstanding saturation mercury uptake capacity can be attributed to the high surface area together with a large number of highly accessible thiol groups that are well dispersed throughout the inner surface of PAF-1-SH.

The ability to withstand a variety of harsh chemical conditions (for example, extreme $\mathrm{pH}$ ) and still effectively adsorb $\mathrm{Hg}$ (II) is highly desirable for a material in practical application of decontaminating $\mathrm{Hg}(\mathrm{II})$ from aqueous media ${ }^{18}$. The chemical/ water stability of PAF-1-SH was verified by virtually no surface area drop after PAF-1-SH sample was treated successively with 2.0 M NaOH, $2.0 \mathrm{M} \mathrm{HCl}$ and boiling water, as revealed by $\mathrm{N}_{2}$ sorption isotherms collected at $77 \mathrm{~K}$ (Supplementary Fig. 8). This represents an advantage of PAF-1-SH for mercury removal across a wide range of $\mathrm{pH}$, particularly when compared with silica and MOFs based adsorbents ${ }^{12-16,29-34}$, which usually suffer from the loss of porosity under such harsh conditions. Mercury adsorption experiments under acid and basic conditions revealed that PAF-1-SH also exhibits high affinities for $\mathrm{Hg}$ (II) with $K_{d}$ values of $6.66 \times 10^{7} \mathrm{mlg}^{-1}$ at $\mathrm{pH} 1.0$ and $2.49 \times 10^{7} \mathrm{mlg}^{-1}$ at $\mathrm{pH} 12.8$, which render excellent capability of reducing $\mathrm{Hg}(\mathrm{II})$ concentrations from 10 p.p.m. to <0.3 p.p.b. at $\mathrm{pH} 1.0$ and $<0.8$ p.p.b. at pH 12.8 (Supplementary Fig. 9). These results highlight the effectiveness of PAF-1-SH as mercury 'nano-trap'

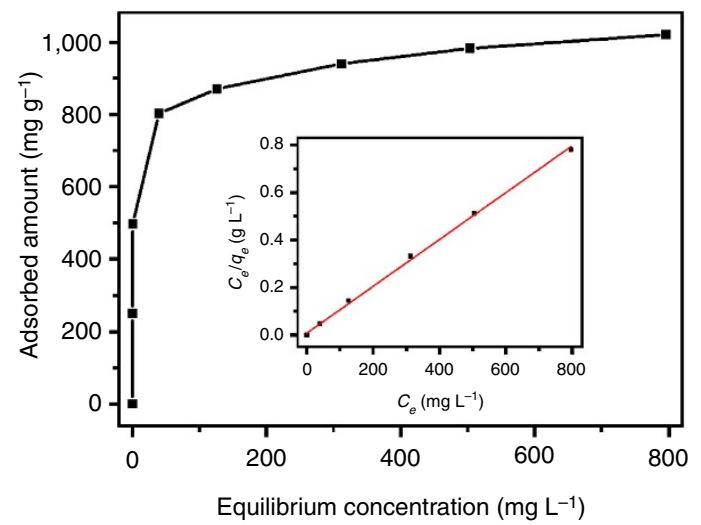

Figure 4 | $\mathbf{H g}$ (II) adsorption isotherm for PAF-1-SH. Inset shows the linear regression by fitting the equilibrium adsorption data with Langmuir adsorption model. for removing $\mathrm{Hg}$ (II) from aqueous media over a broad range of $\mathrm{pH}$ values.

The mercury-loaded PAF-1-SH can be regenerated by washing with a concentrated $\mathrm{HCl}(12.0 \mathrm{M})$ solution, which results in $100 \%$ removal of the loaded mercury. The regenerated PAF-1-SH retained $>90 \%$ of the original loading capacity even after several regeneration and reuse cycles (Supplementary Fig. 10). We reasoned that such excellent recyclability with negligible loss of mercury adsorption capacity observed for PAF-1-SH should be attributed to the well dispersive distribution of thiol groups throughout its highly porous framework structure thus minimizing the formation of the weaker binding $\mathrm{S}-\mathrm{S}$ units as a result from the oxidation - $\mathrm{SH}$ groups. This is supported by the absence of $\mathrm{S}-\mathrm{S}$ stretching bands $\left(500-540 \mathrm{~cm}^{-1}\right)^{47}$ in the FT-IR spectra of regenerated PAF-1-SH (Supplementary Fig. 11).

The selectivity tests were also performed on PAF-1-SH in a $\mathrm{Hg}(\mathrm{II})$ solution containing $\mathrm{Pb}(\mathrm{II}), \mathrm{Cd}(\mathrm{II}), \mathrm{As}(\mathrm{III}), \mathrm{Ca}(\mathrm{II}), \mathrm{Mg}(\mathrm{II})$, $\mathrm{Zn}$ (II) and $\mathrm{Na}$ (I) ions (Table 1). PAF-1-SH not only can effectively adsorb $\mathrm{Hg}(\mathrm{II})$, but also can largely remove other highly toxic heavy metal ions of $\mathrm{Pb}(\mathrm{II})$ and $\mathrm{Cd}(\mathrm{II})$. In contrast, other background metal ions such as $\mathrm{Ca}(\mathrm{II}), \mathrm{Zn}(\mathrm{II}), \mathrm{Mg}(\mathrm{II})$ and $\mathrm{Na}$ (I) do not quite bind to PAF-1-SH, and PAF-1-SH can remain effective in the presence of high concentrations of these ions. Similar results (Table 2) were also obtained in the breakthrough experiments of passing the mixture solution of these ions through a column packed with PAF-1-SH. Similar to FMMS ${ }^{12}$, the high selectivity of $\mathrm{Hg}$ (II) and other heavy metal ions of $\mathrm{Pb}(\mathrm{II})$ and $\mathrm{Cd}(\mathrm{II})$ against the background metal ions of $\mathrm{Ca}(\mathrm{II}), \mathrm{Zn}(\mathrm{II}), \mathrm{Mg}$ (II) and $\mathrm{Na}(\mathrm{I})$ observed for PAF-1-SH should stem from the strong soft-soft interactions between $\mathrm{Hg}$ (II)/ $\mathrm{Pb}$ (II)/Cd(II) ions and the thiol groups within PAF-1-SH. PAF-1-SH also exhibits low binding ability for As(III), and this should be due to that As(III) is a non-metal ion and exists in the form of $\mathrm{AsO}_{2}^{-}$in aqueous solution, which can hardly interact with the thiol group strongly.

Investigation of $\mathbf{H g}(\mathrm{II})$ binding interactions. The outstanding performances of PAF-1-SH as mercury 'nano-trap' can be traceable to the strong binding interactions between $\mathrm{Hg}(\mathrm{II})$ and thiol group in PAF-1-SH, which have been elucidated by FT-IR, NMR and photoluminescence (PL) studies. As shown in Fig. 5a, IR spectra reveal a large shift of $\mathrm{S}-\mathrm{H}$ stretch mode from $2,576 \mathrm{~cm}^{-1}$ in PAF-1-SH to $2,380 \mathrm{~cm}^{-1}$ in the $\mathrm{Hg}(\mathrm{II})$-loaded PAF-1-SH, indicating the formation of strong binding interactions between $\mathrm{Hg}(\mathrm{II})$ and thio group. The formation of strong chemical bonding between the mercury and thiol group is also suggested by solid state ${ }^{13} \mathrm{C}$ NMR spectrum for $\mathrm{Hg}$ (II)-loaded PAF-1-SH (Fig. 5b), which indicates a large shift of 6 p.p.m. for

Table 1 | Concentrations of metal ions before and after the treatment of PAF-1-SH.

Solution

\begin{tabular}{|c|c|c|c|c|c|c|c|c|}
\hline \multirow{2}{*}{ solution } & \multicolumn{8}{|c|}{ Concentration (p.p.m.) } \\
\hline & $\mathrm{Hg}$ (II) & $\mathrm{Pb}(\mathrm{II})$ & Cd(II) & As(III) & $\mathrm{Ca}(\mathrm{II})$ & $\mathrm{Zn}(\mathrm{II})$ & Mg(II) & $\mathrm{Na}(\mathrm{I})$ \\
\hline Before treatment & 3.12 & 2.52 & 1.62 & 0.94 & 0.61 & 0.95 & 0.36 & 8,223 \\
\hline After treatment & 0.0003 & 0 & 0.042 & 0.78 & 0.52 & 0.58 & 0.31 & 8,211 \\
\hline
\end{tabular}

Table 2 | Concentrations of metal ions before and after the breakthrough experiments of PAF-1-SH.

\begin{tabular}{|c|c|c|c|c|c|c|c|c|}
\hline \multirow[t]{2}{*}{ Solution } & \multicolumn{8}{|c|}{ Concentration (p.p.m.) } \\
\hline & Hg(II) & $\mathrm{Pb}(\mathrm{II})$ & Cd(II) & As(III) & $\mathrm{Ca}(\mathrm{II})$ & $\mathrm{Zn}(\mathrm{II})$ & Mg(II) & $\mathrm{Na}(\mathrm{I})$ \\
\hline Before breakthrough & 3.12 & 2.52 & 1.62 & 0.94 & 0.61 & 0.95 & 0.36 & 8,223 \\
\hline After breakthrough & 0 & 0 & 0.025 & 0.73 & 0.45 & 0.44 & 0.28 & 8,193 \\
\hline
\end{tabular}


a

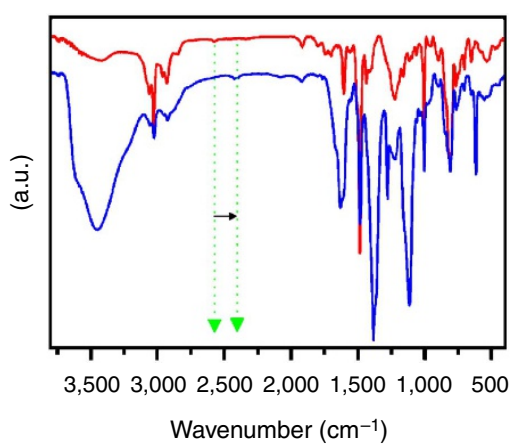

b

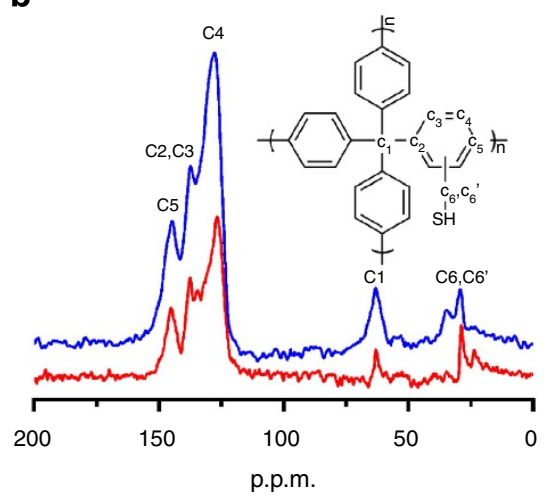

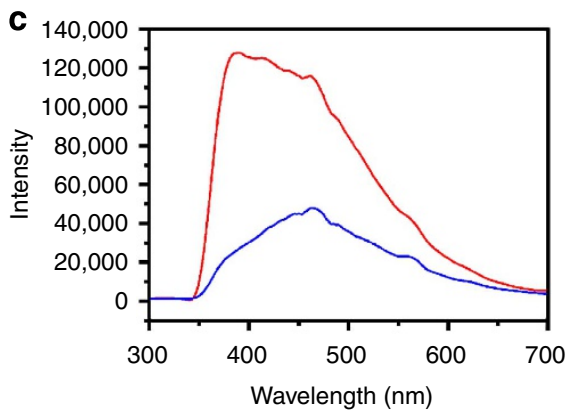

Figure 5 | Spectroscopic analysis of Hg(II) binding interactions. (a) FT-IR spectra of PAF-1-SH (red) and Hg(II)-loaded PAF-1-SH (blue). (b) Solid state ${ }^{13} \mathrm{C}$ NMR of PAF-1-SH (red) and Hg(II)-loaded PAF-1-SH (blue). (c) The PL spectra of PAF-1-SH (red) and Hg(II)-loaded PAF-1-SH (blue).

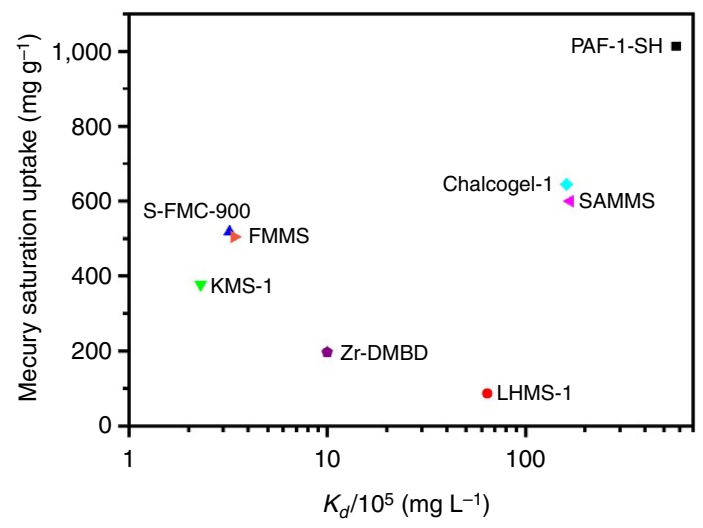

Figure 6 | $\mathbf{H g}$ (II) saturation uptake. Comparision of $\mathrm{Hg}$ (II) saturation uptake amount and $K_{d}$ value for PAF-1-SH with other benchmark porous materials, KMS-1 (ref. 56); LHMS-1 (ref. 50); FMMS (ref. 12); Chalcogel-1 (ref. 19); S-FMC-900 (ref. 18); Zr-DMBD (ref. 34); SAMMS (ref. 57); [a]: $K_{d}$ value referred herein was measured based on the same initial concentration with others).

the peak corresponding to the carbon $\left(\mathrm{C} 6 / \mathrm{C}^{\prime}\right)$ attached to the thiol group. The strong binding interactions between $\mathrm{Hg}(\mathrm{II})$ and thiol group in PAF-1-SH are further evidenced by PL studies, which reveal that the PL intensity of PAF-1-SH host framework is greatly impacted by the $\mathrm{Hg}$ (II) uptake. As shown in Fig. $5 c$, the as-made sample features a broad emission centred around $420 \mathrm{~nm}$, and the PL intensity is largely suppressed on the loading of $\mathrm{Hg}(\mathrm{II})$, being $<1 / 3$ of the intensity for the host PAF-1-SH.

\section{Discussion}

To evaluate a material for mercury removal from aqueous solutions, the distribution coefficient $\left(K_{d}\right)$ and saturation uptake capacity have been deemed as two most important criteria, and high values for both of them are needed to achieve high effectiveness and high efficiency for mercury removal. Exceptional distribution coefficient for $\mathrm{Hg}(\mathrm{II})$ and extraordinary mercury saturation uptake capacity have both been demonstrated in the POP-based mercury 'nano-trap' of PAF-1-SH as reported herein, which sets a new benchmark for mercury adsorbent materials (Fig. 6). The issues of structure stability under harsh chemical conditions, decreasing mercury affinity over a broad range of $\mathrm{pH}$ and loss of mercury uptake capacity on regeneration represent some barriers for most mercury adsorbent materials to be applied in practical application of decontaminating $\mathrm{Hg}$ (II) from aqueous media; these issues have also been well addressed in the POP-based mercury 'nano-trap' of PAF-1-SH. A high selectivity of $\mathrm{Hg}(\mathrm{II})$ against a series of trace metal ions (for example, $\mathrm{Ca}(\mathrm{II}), \mathrm{Zn}(\mathrm{II}), \mathrm{Mg}(\mathrm{II}), \mathrm{Na}(\mathrm{I})$ ) represents another necessary consideration for mercury removal from aqueous solutions in reality, and this has been well demonstrated by the POP-based mercury 'nano-trap' of PAF-1-SH as well. The decent thermal stability up to $270^{\circ} \mathrm{C}$ (Supplementary Fig. 12) for PAF-1SH suggests its capability for mercury vapour sorption, which is related to the industrial processes of flue gas detoxification ${ }^{55}$; this aspect of work will be conducted in the near future. Albeit the high cost of PAF-1 would be a concern for the practical utilization of PAF-1-SH for mercury removal, the mercury 'nano-traps' can be readily achieved in other POPs ${ }^{35}$ that are constructed from various organic building blocks derived from a variety of resources through economical reaction processes, thus paving a way to develop 'nano-traps' as a new platform for mercury removal.

In conclusion, we have demonstrated the creation of mercury 'nano-trap' for highly effective and highly efficient removal of $\mathrm{Hg}(\mathrm{II})$ from aqueous solutions as exemplified in the context of thiol-functionalized POP of PAF-1, PAF-1-SH. PAF-1-SH exhibits very high affinity for $\mathrm{Hg}(\mathrm{II})$ with an exceptional 
distribution coefficient value of $5.76 \times 10^{7} \mathrm{ml} \mathrm{g}^{-1}$, extremely fast kinetics for $\mathrm{Hg}$ (II) adsorption with an extraordinary pseudosecond-order adsorption rate constant of $8.13 \mathrm{~g} \mathrm{mg}^{-1} \mathrm{~min}^{-1}$, and record-high saturation mercury uptake capacity of $1,014 \mathrm{mg} \mathrm{g}^{-1}$. As mercury 'nano-trap', PAF-1-SH not only can effectively reduce $\mathrm{Hg}(\mathrm{II})$ concentration from 10 p.p.m. to the extremely low level of $<0.4$ p.p.b. well below the acceptable limits in drinking water standards ( $<2$ p.p.b.) and efficiently remove $>99.9 \%$ mercury(II) within a few minutes, but also can retain high effectiveness for mercury removal over a very broad $\mathrm{pH}$ range and maintain high mercury adsorption capacity on regeneration and reuse; in addition, it can remain effective in the presence of high concentrations of background metal ions of $\mathrm{Ca}(\mathrm{II}), \mathrm{Zn}(\mathrm{II}), \mathrm{Mg}(\mathrm{II})$ and $\mathrm{Na}(\mathrm{I})$. Our approach of creating mercury 'nano-traps' based on highly porous and highly robust POPs thereby provides a new perspective for decontaminating $\mathrm{Hg}(\mathrm{II})$ from aqueous media. Moreover, the 'nano-traps' advanced herein can also be readily applied to capturing other heavy metal ions from contaminated water for environmental remediation as preliminarily demonstrated here, and the details of this aspect of work are currently under continuation in our laboratory.

\section{Methods}

Materials and measurements. Commercially available reagents were purchased in high purity and used without further purification. Powder X-ray diffraction (PXRD) data were collected on a Bruker AXS D8 Advance A25 Powder X-ray Diffractometer. $\mathrm{N}_{2}$ gas sorption experiments were carried out on a Micrometrics ASAP2020 volumetric gas sorption instrument. Elemental analyses were performed on a Perkin-Elmer 2400 element analyser. TGA was analysed by using a Q50 thermogravimetric analyser. IR spectra were recorded on a Nicolet Impact 410 FTIR spectrometer. XPS measurements were performed on an ESCALAB 250 $\mathrm{X}$-ray photoelectron spectroscopy, using $\mathrm{Mg} \mathrm{K} \alpha \mathrm{X}$-ray as the excitation source. The ${ }^{13} \mathrm{C}$ NMR data were collected on a Bruker AVANCE IIIHD console with a 1.9-mm MAS probe. The scanning electron microscope analysis was performed on a JEOL JSM-6700F and Hitachi S-4800 field-emission scanning electron microscope (FE-SEM). ICP was performed on a Perkin-Elmer Elan DRC II Quadrupole Inductively Coupled Plasma Mass Spectrometer (ICP-MS) analyser.

Synthesis of PAF-1-SH. A re-sealable flask was charged with PAF-1 $(200.0 \mathrm{mg})$, paraformaldehyde $(1.0 \mathrm{~g})$, glacial $\mathrm{AcOH}(6.0 \mathrm{ml}), \mathrm{H}_{3} \mathrm{PO}_{4}(3.0 \mathrm{ml})$ and conc. $\mathrm{HCl}$ $(20.0 \mathrm{ml})$. The flask was sealed and heated to $90^{\circ} \mathrm{C}$ for 3 days. The resulting solid was collected, washed with water and methanol, and then dried under vacuum to produce yellow solid of PAF-1- $\mathrm{CH}_{2} \mathrm{Cl}$. Subsequently the obtained PAF-1- $\mathrm{CH}_{2} \mathrm{Cl}$ was mixed with $\mathrm{NaHS}(1.2 \mathrm{~g}, 21.0 \mathrm{mmol})$ in $100 \mathrm{ml} \mathrm{EtOH}$ under $\mathrm{N}_{2}$ and stirred at $75^{\circ} \mathrm{C}$ for 3 days. The resulting solid was collected, washed with water and methanol, and then dried under vacuum to produce PAF-1-SH as yellow powder. Elemental Analysis: C: $72.5 \%$; H: 4.24\%; S: $17.6 \%$.

Synthesis of MCM-41-SH. The MCM-41-SH was synthesized according to the procedures reported in the literature ${ }^{14}$. Elemental analysis: C: $8.54 \%$; $\mathrm{H}: 1.81$; S: $4.99 \%$.

Hg(II) sorption kinetics. A $50 \mathrm{ml}$ aqueous of $\mathrm{Hg}\left(\mathrm{NO}_{3}\right)_{2}$ (10 p.p.m., $\mathrm{pH}=6.8$ $\mathrm{NaH}_{2} \mathrm{PO}_{4} / \mathrm{Na}_{2} \mathrm{HPO}_{4}$ buffer) was added to an Erlenmeyer flask. Then $25.0 \mathrm{mg}$ PAF-1-SH sample was added to form a slurry. The mixture was stirred at room temperature for $8 \mathrm{~h}$. During the stirring period, the mixture was filtered at intervals through a $0.45-\mu \mathrm{m}$ membrane filter for all samples, then the filtrates were analysed using ICP-MS to determine the remaining $\mathrm{Hg}$ (II) content.

Hg(II) sorption isotherm. PAF-1-SH $(10.0 \mathrm{mg})$ was added to each Erlenmeyer flask containing $\mathrm{Hg}\left(\mathrm{NO}_{3}\right)_{2}$ solution $(50 \mathrm{ml})$ with different concentrations. The mixtures were stirred at room temperature for $12 \mathrm{~h}$, and then were filtered separately through a $0.45-\mu \mathrm{m}$ membrane filter, and the filtrates were analysed by using ICP-MS to determine the remaining $\mathrm{Hg}(\mathrm{II})$ content.

Ion selectivity tests. Fifty milligrams of PAF-1-SH sample was added into an Erlenmeyer flask containing a 50 -ml aqueous solution of $\mathrm{Hg}\left(\mathrm{NO}_{3}\right)_{2}, \mathrm{~Pb}\left(\mathrm{NO}_{3}\right)_{2}$, $\mathrm{NaAsO}_{2}, \mathrm{Cd}\left(\mathrm{NO}_{3}\right)_{2}, \mathrm{Zn}\left(\mathrm{NO}_{3}\right)_{2}, \mathrm{Ca}\left(\mathrm{NO}_{3}\right)_{2}, \mathrm{Mg}\left(\mathrm{NO}_{3}\right)_{2}$ with sorts of concentration in $\mathrm{NaH}_{2} \mathrm{PO}_{4} / \mathrm{Na}_{2} \mathrm{HPO}_{4}$ buffer $(\mathrm{pH}=6.8)$. The mixture in the form of slurry was stirred at room temperature for $12 \mathrm{~h}$, and then was filtered through a $0.45-\mu \mathrm{m}$ membrane filter, and the filtrates were analysed using ICP-MS to determine the contents.
Breakthrough experiments. Hundred milligrams of PAF-1-SH sample was packed into a pipette to form an adsorption column with inner diameter of $\sim 3.3 \mathrm{~mm}$ and the packed sample length was about $7.8 \mathrm{~cm}$. An aqueous solution (30 ml) of $\mathrm{Hg}\left(\mathrm{NO}_{3}\right)_{2}, \mathrm{~Pb}\left(\mathrm{NO}_{3}\right)_{2}, \mathrm{NaAsO}_{2}, \mathrm{Cd}\left(\mathrm{NO}_{3}\right)_{2}, \mathrm{Zn}\left(\mathrm{NO}_{3}\right)_{2}, \mathrm{Ca}\left(\mathrm{NO}_{3}\right)_{2}$, $\mathrm{Mg}\left(\mathrm{NO}_{3}\right)_{2}$ with sorts of concentration in $\mathrm{NaH}_{2} \mathrm{PO}_{4} / \mathrm{Na}_{2} \mathrm{HPO}_{4}$ buffer $(\mathrm{pH}=6.8)$ was then passed through the column, and the filtrates were analysed using ICP-MS to determine the contents.

\section{References}

1. McNutt, M. Mercury and health. Science 341, 1430 (2013).

2. Lubick, N. \& Malakoff, D. With pact's completion, the real work Begins. Science 341, 1443-1445 (2013).

3. Malakoff, D. Taming a mercurial element. Science 341, 1442-1443 (2013).

4. Basic Information about mercury (inorganic) in drinking water. http:// water.epa.gov/drink/contaminants/basicinformation/mercury.cfm\#four.

5. United States Environmental Protection Agency (EPA). Treatment technologies for mercury in soil, waste, and water; EPA Report EPA-542-R-07-003 (U.S. EPA, 2007).

6. Atwood, D. A. \& Zaman, M. K. Mercury removal from water. Struct. Bonding 120, 163-182 (2006).

7. Huang, C. P. \& Blankenship, D. W. The removal of mercury(II) from dilute aqueous solution by activated carbon. Water Res. 18, 37-46 (1984).

8. Blanchard, G., Maunaye, M. \& Martin, G. Removal of heavy metals from water by means of natural zeolites. Water Res. 18, 1501-1507 (1984).

9. Benhammou, A., Yaacoubi, A., Nibou, L. \& Tanouti, B. Adsorption of metal ions onto Moroccan stevensite: kinetic and isotherm studies. J. Colloid. Interface Sci. 282, 320-326 (2005).

10. Tchinda, A. J. et al. One-step preparation of thiol-functionalized porous clay heterostructures: application to $\mathrm{Hg}$ (II) binding and characterization of mass transport issues. Chem. Mater. 21, 4111-4121 (2009).

11. Chiarle, S., Ratto, M. \& Rovvati, M. Mercury removal from water by ion exchange resins adsorption. Water Res. 34, 2971-2978 (2000).

12. Feng, X. et al. Functionalized monolayers on ordered mesoporous supports. Science 276, 923-926 (1997).

13. Liu, J. et al. Hybrid mesoporous materials with functionalized monolayers. $A d v$. Mater. 10, 161-165 (1998).

14. Mercier, L. \& Pinnavaia, T. J. Access in mesoporous materials: advantages of a uniform pore structure in the design of a heavy metal ion adsorbent for environmental remediation. Adv. Mater. 9, 500-503 (1997).

15. Billinge, S. J. L. et al. Mercury binding sites in thiol-functionalized mesostructured silica. J. Am. Chem. Soc. 127, 8492-8498 (2005).

16. Bibby, A. \& Mercier, L. Mercury(II) ion adsorption behavior in thiolfunctionalized mesoporous silica microspheres. Chem. Mater. 14, 1591-1597 (2002).

17. Wang, J. et al. Adsorption of aqueous $\mathrm{Hg}(\mathrm{II})$ by sulfur-impregnated activated carbon. Environ. Eng. Sci. 26, 1693-1699 (2009).

18. Shin, Y. et al. Sulfur-functionalized mesoporous carbon. Adv. Funct. Mater. 17, 2897-2901 (2007).

19. Bag, S., Trikalitis, P. N., Chupas, P. J., Armatas, G. S. \& Kanatzidis, M. G. Porous semiconducting gels and aerogels from chalcogenide clusters. Science 317, 490-493 (2007).

20. Manos, M. J., Malliakas, C. D. \& Kanatzidis, M. G. Heavy-metal-ion capture, ion-exchange, and exceptional acid stability of the open-framework chalcogenide $\left(\mathrm{NH}_{4}\right)_{4} \mathrm{In}_{12} \mathrm{Se}_{20}$. Chem. Eur. J. 13, 51-58 (2007).

21. He, F. et al. Rapid removal of $\mathrm{Hg}(\mathrm{II})$ from aqueous solutions using thiolfunctionalized Zn-doped biomagnetite particles. ACS Appl. Mater. Interfaces 4, 4373-4379 (2012).

22. Zhou, H.-C., Long, J. R. \& Yaghi, O. M. Introduction to metal-organic frameworks. Chem. Rev. 112, 673-674 (2012).

23. Uemura, T. et al. Unveiling thermal transitions of polymers in subnanometre pores. Nat. Commun. 1, 83 (2010).

24. An, J. et al. Metal-adeninate vertices for the construction of an exceptionally porous metal-organic framework. Nat. Commun. 3, 604 (2012).

25. Xiang, S. et al. Microporous metal-organic framework with potential for carbon dioxide capture at ambient conditions. Nat. Commun. 3, 954 (2012).

26. Zhao, X. et al. Selective anion exchange with nanogated isoreticular positive metal-organic frameworks. Nat. Commun. 4, 2344 (2013).

27. Sun, C.-Y. et al. Efficient and tunable white-light emission of metalorganic frameworks by iridium-complex encapsulation. Nat. Commun. 4, 2717 (2013).

28. Li, L. et al. A synthetic route to ultralight hierarchically micro/mesoporous Al(III)-carboxylate metal-organic aerogels. Nat. Commun. 4, 1774 (2013).

29. Zhou, X.-P., Xu, Z., Zellerb, M. \& Hunter, A. D. Reversible uptake of $\mathrm{HgCl}_{2}$ in a porous coordination polymer based on the dual functions of carboxylate and thioether. Chem. Commun. 5439-5441 (2009).

30. Fang, Q.-R. et al. Functional mesoporous metal-organic frameworks for the capture of heavy metal ions and size-selective catalysis. Inorg. Chem. 49, 11637-11642 (2010). 
31. He, J. et al. Thioether side chains improve the stability, fluorescence, and metal uptake of a metal-organic framework. Chem. Mater. 23, 2940-2947 (2011).

32. Ke, F. et al. Thiol-functionalization of metal-organic framework by a facile coordination-based postsynthetic strategy and enhanced removal of $\mathrm{Hg}^{2+}$ from water. J. Hazard. Mater. 196, 36-43 (2011).

33. Khan, N. A., Hasan, Z. \& Jhung, S. H. Adsorptive removal of hazardous materials using metal-organic frameworks (MOFs): A review. J. Hazard. Mater. 244-245, 444-456 (2013).

34. Yee, K.-K. et al. Effective mercury sorption by thiol-laced metal - organic frameworks: in strong acid and the vapor phase. J. Am. Chem. Soc. 135, 7795-7798 (2013).

35. Cooper, A. I. Conjugated microporous polymers. Adv. Mater. 21, 1291-1295 (2009).

36. Thomas, A. Functional materials: from hard to soft porous frameworks. Angew. Chem. Int. Ed. 49, 8328-8344 (2010).

37. Yuan, D., Lu, W., Zhao, D. \& Zhou, H.-C. Highly stable porous polymer networks with exceptionally high gas-uptake capacities. Adv. Mater. 23, 3723-3725 (2011)

38. Lu, W. Sulfonate-grafted porous polymer networks for preferential $\mathrm{CO}_{2}$ adsorption at low pressure. J. Am. Chem. Soc. 133, 18126-18129 (2011).

39. Zhu, X. et al. A superacid-catalyzed synthesis of porous membranes based on triazine frameworks for $\mathrm{CO}_{2}$ separation. J. Am. Chem. Soc. 134, 10478-10484 (2012).

40. Lu, W. et al. Polyamine-tethered porous polymer networks for carbon dioxide capture from Flue Gas. Angew. Chem. Int. Ed. 51, 7480-7484 (2012).

41. Weston, M. H. et al. Synthesis and metalation of catechol-functionalized porous organic polymers. Chem. Mater. 24, 1292-1296 (2012).

42. Xu, Y., Jin, S., Xu, H., Nagai, A. \& Jiang, D. Conjugated microporous polymers: design, synthesis and application. Chem. Soc. Rev. 42, 8012-8031 (2013).

43. Chandra, S. et al. Chemically stable multilayered covalent organic nanosheets from covalent organic frameworks via mechanical delamination. J. Am. Chem. Soc. 135, 17853-17861 (2013).

44. Gu, J. et al. Conjugated organic framework with three-dimensionally ordered stable structure and delocalized $\pi$ clouds. Nat. Commun. 4, 2736 (2013).

45. Cohen, S. M. Postsynthetic methods for the functionalization of metal-organic frameworks. Chem. Rev. 112, 970-1000 (2012).

46. Ben, T. et al. Targeted synthesis of a porous aromatic framework with high stability and exceptionally high surface area. Angew. Chem. Int. Ed. 48, 9457-9460 (2009)

47. Bellamy, L. J. The infrared spectra of complex molecules (Wiley, 1958).

48. Enomoto, I., Nakamura, I., Soeda, S. \& Yamaguchi, K. Immobilization of dyeing sites to polyethylene by plasma treatment. J. Photopolym. Sci. Technol. 26, 539-544 (2013).

49. Do, D. D. in Adsorption Analysis: Equilibria And Kinetics (ed. Yang, R. T.) 57 (Imperial College Press, 1998).

50. Manos, M. J., Petkov, V. G. \& Kanatzidis, M. G. $\mathrm{H}_{2 \times} \mathrm{Mn}_{\mathrm{x}} \mathrm{Sn}_{3-\mathrm{x}} \mathrm{S}_{6}(\mathrm{x}=0.11-0.25)$ : a novel reusable sorbent for highly specific mercury capture under extreme $\mathrm{pH}$ conditions. Adv. Funct. Mater. 19, 1087-1092 (2009).
51. Ho, Y.-S. Review of second-order models for adsorption systems. J. Hazard. Mater. B136, 681-689 (2006).

52. Qu, R. J. et al. Adsorption kinetics and isotherms of $\mathrm{Ag}(\mathrm{I})$ and $\mathrm{Hg}$ (II) onto silica gel with functional groups of hydroxyl- or amino-terminated polyamines. J. Chem. Eng. Data 56, 1982-1990 (2011).

53. Qu, R. et al. Adsorption of $\mathrm{Hg}$ (II) from an aqueous solution by silica-gel supported diethylenetriamine prepared via different routes: kinetics, thermodynamics and isotherms. J. Chem. Eng. Data 55, 1496-1504 (2010).

54. Rostamian, R., Najafi, M. \& Rafati, A. A. Synthesis and characterization of thiolfunctionalized silica nano hollow sphere as a novel adsorbent for removal of poisonous heavy metal ions from water: kinetics isotherms and error analysis. Chem. Eng. J. 171, 1004-1011 (2011).

55. O’Dowd, W. J., Hargis, R. A., Granite, E. J. \& Pennline, H. W. Recent advances in mercury removal technology at the National Energy Technology Laboratory. Fuel Process Technol. 85, 533-548 (2004).

56. Manos, M. J. \& Kanatzidis, M. G. Sequestration of heavy metals from water with layered metal sulfides. Chem. Eur. J. 15, 4779-4784 (2009).

57. Chen, X. et al. Mercury separation and immobilization and immobilization using separation and immobilization using self-assembled monolayers on mesoporous supports (SAMMS). Sep. Sci. Technol. 34, 1121-1132 (1999).

\section{Acknowledgements}

We acknowledge the University of South Florida for financial support of this work. We thank Professor Qisheng Huo for his kind suggestions and help.

\section{Author contributions}

S.M. conceived and designed the research. S.M., B.L. and Y.Z. co-wrote the manuscript B.L. and Y.Z. carried out the materials design, synthesis and characterization as well as performed mercury sorption experiments and data analysis. D.M. and Z.S. contributed to material characterization. All authors discussed the results and commented on the manuscript.

\section{Additional information}

Supplementary Information accompanies this paper at http://www.nature.com/ naturecommunications

Competing financial interests: The authors declare no competing financial interests.

Reprints and permission information is available online at http://npg.nature.com/ reprintsandpermissions/

How to cite this article: Li, B. et al. Mercury nano-trap for effective and efficient removal of mercury(II) from aqueous solution. Nat. Commun. 5:5537 doi: 10.1038/ncomms6537 (2014). 